\title{
Broad-scale patterns in local diversity of marine benthic harpacticoid copepods (Crustacea)
}

\author{
Andrey I. Azovsky ${ }^{1, *}$, Lesya A. Garlitska ${ }^{2}$, Elena S. Chertoprud ${ }^{1}$ \\ ${ }^{1}$ Department of Hydrobiology, Biology Faculty, Moscow State University, Moscow 119899, Russia \\ ${ }^{2}$ Odessa Branch of the Institute of Biology of Southern Seas, NASU, Odessa 65125, Ukraine
}

\begin{abstract}
The $\alpha$ and $\beta$ diversity of benthic harpacticoids were estimated using 103 published datasets from all over the world, with depths ranging from the intertidal zone to $5600 \mathrm{~m}$. $\alpha$ diversity (expected number of species per 100 individuals) was correlated with organic matter flux to the bottom, and this effect was depth-dependent, with the correlation being negative from the shallowest waters up to $33 \mathrm{~m}$ and positive in deeper waters. $\alpha$ diversity was also positively correlated with depth itself and depended on the sediment properties and duration of study, but showed no latitudinal trend. $\beta$ diversity (estimated as the slope of the species accumulation curve) was negatively correlated with latitude and positively correlated with the spatial extent and depth range of sampling. The effect of latitude and extent was mainly pronounced for the intertidal zone, whereas the depth range was the most significant factor in the deep waters. Additionally, $\beta$ diversity was higher on sands and mixed sediments than on silt or mud. Latitude explained $45 \%$ of the $\beta$ diversity variation in the littoral zone, $18 \%$ in the upper sublittoral, and less than $5 \%$ in deeper zones. Thus, $\alpha$ and $\beta$ diversity act as independent and spatially uncorrelated components of overall regional diversity, driven by different mechanisms. Variations in $\beta$ diversity presumably reflect spatial heterogeneity and form the latitudinal gradient in the shallowest waters. Deeper, trophic conditions play the leading role, and thus $\alpha$ diversity contributes the major proportion of the total diversity variance there and is responsible for the bathymetric gradient.
\end{abstract}

KEY WORDS: Harpacticoida $\cdot \alpha$ diversity $\cdot \beta$ diversity $\cdot$ Latitude $\cdot$ Depth $\cdot$ Productivity

\section{INTRODUCTION}

Latitudinal and (in the marine realm) bathymetric gradients of species diversity are the most well known and widely discussed ecological patterns. A number of hypotheses attempt to explain these patterns, but some basic aspects remain insufficiently explored, including their commonality, causes, and the role of diversity components (Rosenzweig 1995, Willig et al. 2003, Gaston \& Spicer 2004).

Biological diversity within a region, termed $\gamma$ diversity, may be partitioned into 2 components (Rosenzweig 1995, Gray 2000, and references therein). The first component is inventory diversity (or $\alpha$ diversity), which is the number of species in a single place (sam- pling unit). The second component, differentiation diversity, more commonly referred to as $\beta$ diversity, quantifies the turnover in species across space, between places, habitats, or sampling units. In theory, each component of diversity is mainly controlled by its own set of factors and processes. However, we still have little empirical evidence for generalizations about these factors.

Most large-scale studies concern changes in $\alpha$ diversity, which commonly decreases polewards and demonstrates a unimodal bathymetric trend, but the strength and slope of these gradients vary across domains, taxa, and regions (reviewed by Rosenzweig 1995, Levin et al. 2001, Hillebrand 2004). In particular, the asymmetry of the latitudinal gradient about 
the equator has been observed for some groups, e.g. foraminiferans (Culver \& Buzas 2000) or marine macrobenthos (Rex et al. 1993, Gray 2002). Nevertheless, comprehensive meta-analysis does not show any consistent differences between hemispheres, despite some variations among the oceans (Hillebrand 2004). The strength of the gradient varies systematically with body mass across organism groups, generally decreasing or even vanishing for the smallest organisms (Hillebrand \& Azovsky 2001, Hillebrand 2004). For macrofauna, latitudinal patterns are not identical, however. Some of regional studies have failed to detect this pattern (e.g. peaks in diversity at midlatitude in both Atlantic and Pacific gastropods, Roy et al. 1998); or even showed regionally opposite trends (Renaud et al. 2009 and references therein). It is unclear whether these differences are caused by regional peculiarities or by the restricted geographical range of stations sampled (Renaud et al. 2009). Furthermore, regional diversity shows consistently stronger and steeper latitudinal gradients than local $(\alpha)$ diversity (Clarke \& Lidgard 2000, Hillebrand 2004), thus posing the question of systematic variation in $\beta$ diversity (see below).

A nonlinear (unimodal) diversity-depth relationship is generally considered as the common pattern that has been reported for both macrobenthos (bivalves, gastropods, amphipod crustaceans, and other groups; Stuart et al. 2003, McClain et al. 2009, Renaud et al. 2009, and references therein) and meiobenthos (nematodes and harpacticoids; Vanhove et al. 1999, Rex et al. 2001, Lambshead \& Boucher 2003, Muthumbi et al. 2004, Baguley et al. 2006), although the depth of peak diversity varies tremendously among taxa and basins. Explanations of this unimodal pattern are many, involving complex interactions among productivity, disturbance regime, speciation rates, habitat heterogeneity, and patch dynamics, all of which are related to depth.

Spatial gradients in productivity are widely believed to influence species diversity, but this relationship is not a simple one. Mittelbach et al. (2001) provided the first large-scale, formal meta-analysis of diversity-productivity relationships, based on 257 datasets, both terrestrial and aquatic, from 171 publications. Their central findings were that there is no single general pattern and that patterns are scale and taxon dependent, with local diversity most often demonstrating a unimodal (hump-shaped) response. For marine benthos in particular, studies that use direct measures of productivity, such as particulate organic carbon (POC) flux, sediment organic content, and carbon burial rates, appear to provide conflicting results, such that diversity varies positively, negatively, or unimodally with productivity (Levin et al. 2001). As Levin et al. (2001) hypothesized, these particular results may represent ranges of food availability that occupy different segments of a hump-shaped diversity-productivity relationship, from ascending at low levels of productivity to descending at high levels.

$\beta$ diversity at large spatial scales has been studied less intensively. While some studies have found that $\beta$ diversity decreases with increasing latitude (e.g. for mammals, birds, trees, or shallow-water bryozoans; Clarke \& Lidgard 2000, Willig et al. 2003), others have found the opposite trend or no correlation at all (Koleff et al. 2003a, Okuda et al. 2004a,b). Similarly, the observed relationships between $\alpha$ and $\beta$ diversity have been very variable (Koleff \& Gaston 2002). Differences in the taxa studied, locations, and spatial scale as well as variation in methods applied make it difficult to discern whether there are general patterns in $\beta$ diversity. Questions regarding the determinants of diversity components can only be answered once there is knowledge of broad-scale patterns. Unfortunately, both diversity components have been rarely investigated simultaneously on the same dataset. In particular, very few $\beta$ diversity measures deal with meiofauna, although high rates of species turnover have been reported in several regional studies (Muthumbi et al. 2004, 2011, Danovaro et al. 2009).

Large-scale diversity patterns have mainly been studied for large organisms, such as higher plants, vertebrates, or marine macrofauna, while the meiofauna is less explored in this respect. Decreasing $\alpha$ diversity with increasing latitude has been shown for deep-sea benthic foraminifera (Culver \& Buzas 2000, Corliss at al. 2009). For nematodes, the results are equivocal, and whether latitude or depth primarily determines the observed patterns is a matter of discussion (Lambshead et al. 2000, Rex et al. 2001, Mokievsky \& Azovsky 2002, Lambshead \& Boucher 2003). For example, compilation of the published data did not reveal any prominent latitudinal gradients for shallow water free-living marine nematodes in the southern hemisphere, whereas the samples collected specifically along the coast of Chile between 18 and $42^{\circ} \mathrm{S}$ showed that sandy beach nematode fauna follows the classic latitudinal gradient (Boucher 1990, Lee \& Riveros 2011). The wider inter-regional comparisons, however, did not show obvious latitudinal trends in nematode $\alpha$ diversity, in contrast to macrofauna (Vanhove et al. 1999, Mokievsky \& Azovsky 2002, Muthumbi et al. 2004). 
Harpacticoids, aside from nematodes, are ubiquitous and often the most abundant component of marine meiofauna (Giere 2009). Unlike many macrobenthic groups, harpacticoids recruit directly to the benthic environment, i.e. have no long pelagic dispersal phase. High diversity, abundance, and ubiquitousness make them an important target group for marine macroecological research. However, their global distributional patterns remain unexplored, since most studies are local or at best regional. The few large-scale comparisons of harpacticoid assemblages (Chertoprud et al. 2010, 2011, Veit-Köhler et al. 2010) are also geographically limited and do not address either latitudinal or bathymetric patterns.

In sum, these results suggest that multiple factors are responsible for generating and maintaining biodiversity of the benthos. Several important questions, however, remain unsettled: Do any underlying global patterns exist in benthic diversity, despite regional environmental influence? Are these patterns, if they exist, similar for different groups of macro- and meiofauna? What is the role of different diversity components in maintaining these patterns?

Here, we provide the first joint, global-scale analysis of the $\alpha$ and $\beta$ diversity of marine benthic harpacticoids. An extensive database compiled from many published sources was used to explore the global trends in $\alpha$ and $\beta$ diversity related to water depth and latitude. In the process, we also tested for the effects of potentially important ecological variables and sampling properties.

\section{MATERIALS AND METHODS}

\section{Database}

We focused on the fauna of soft sediments because it is the most diverse and well-studied component of the harpacticoid fauna (Giere 2009, Chertoprud et al. 2010). The database employed here included available sample-based data compiled from many sources. Only those datasets were selected in which identifications were made to the species level. A total of 103 datasets from various sites were used from all around the world (Fig. 1). These datasets were sufficiently distant from each other so that spatially autocorrelative effects could be eliminated from the analyses.

The distributions of the datasets across depth, latitude, and spatial scales and sample sizes are shown in Fig. 2. The data covered a wide bathymetric range from 0 to $5600 \mathrm{~m}$. The essential part of the data (38 sets) comes from the intertidal zone, while intermedi-

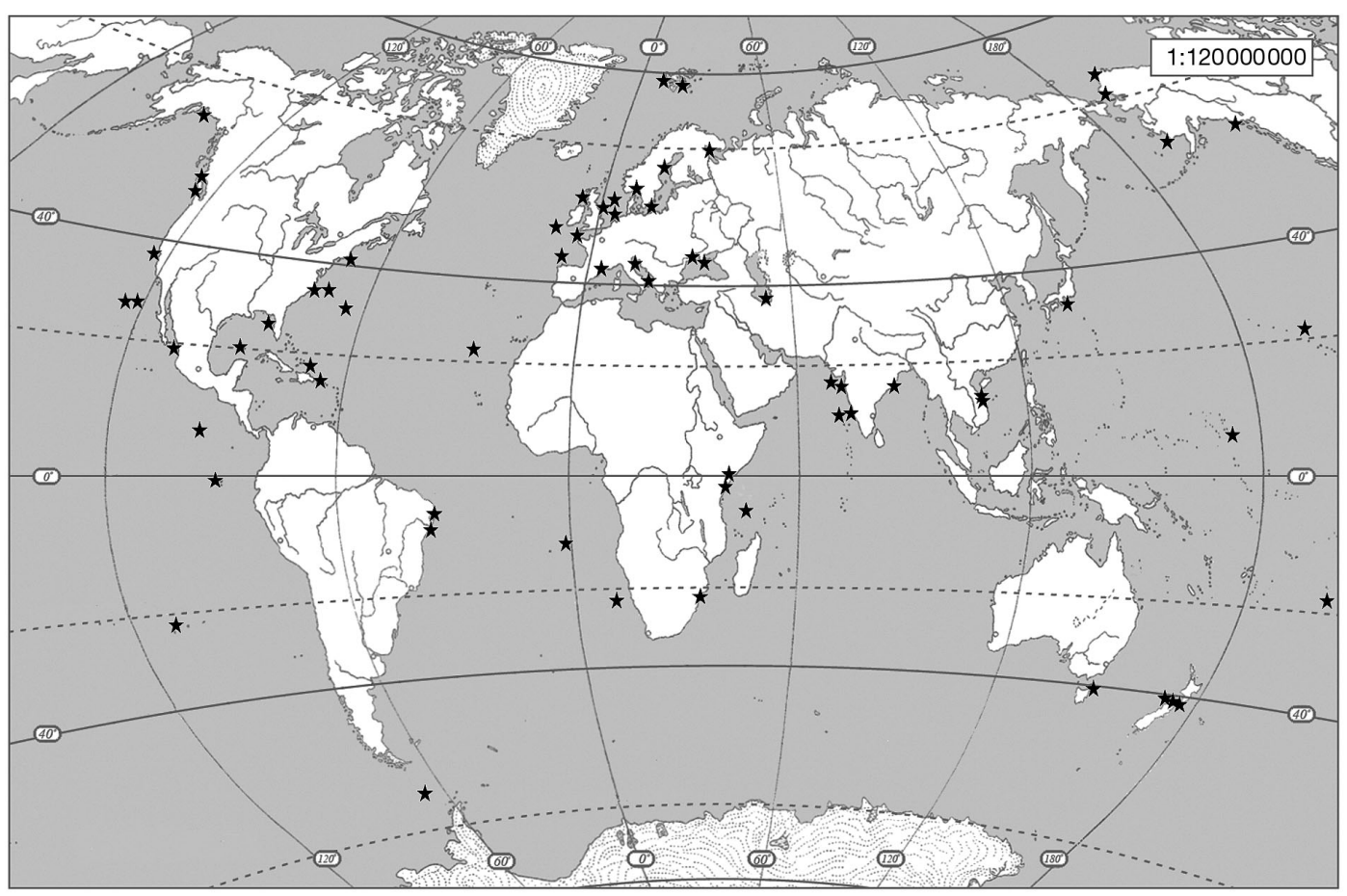

Fig. 1. Sampling sites from which data were used. See Table S1 in the supplement for details (available at www.int-res.com/ articles/suppl/m460p063_supp.pdf) 

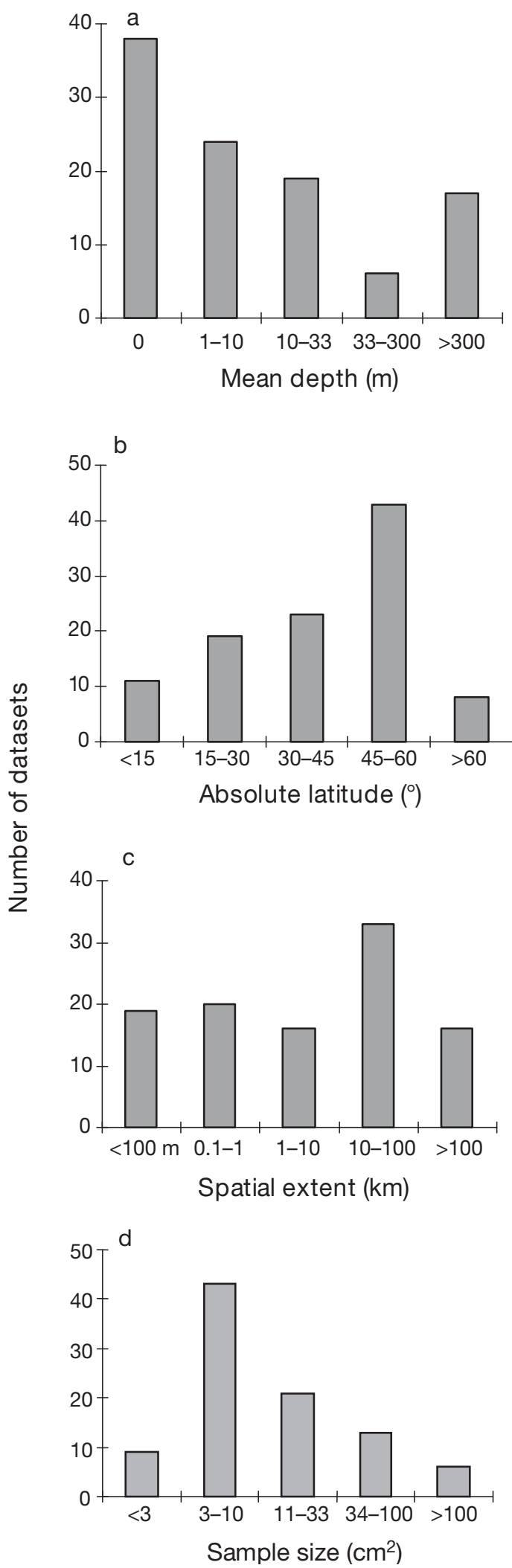

Fig. 2. Distribution of the data sets by (a) depth, (b) absolute latitude, (c) spatial scale of the study, and (d) sample size used ate shelf depths are the least explored (6 sets). Geographically, the majority of the studies have been carried out in the temperate zone $\left(30-60^{\circ} \mathrm{N}\right.$ or S), while there are relatively few data on low and high latitudes. The spatial ranges (measured as the distance between the most distant sampling points for a dataset) varied broadly, with a prevalence of the intermediate-scale studies covering 10 to $100 \mathrm{~km}$. The datasets also differed in the size of the individual samples used, although standard samples of approximately $10 \mathrm{~cm}^{2}$ were used most often. The detailed characteristics of the datasets are shown in Table S1 in the supplement (available at www.int-res.com/ articles/suppl/m460p063_supp.pdf).

\section{Explanatory variables}

For each dataset, the following variables were used as diversity predictors (abbreviations and units are given in square brackets; 'log' denotes the decimal logarithm transformation):

- absolute latitude [LAT, degrees];

- longitude [LONG, degrees];

- spatial extent of the study (distance between the most distant sampling points) [SPAT_RANGE, log $\mathrm{km}]_{i}$

- mean depth [DEPTH, log m]

- depth range between the shallowest and deepest sampling points [DEPTH_RANGE, log $\mathrm{m}]$, not used for intertidal sets;

- sediment properties [SEDIM, coded]; because grain-size data were not always available, we use the following coding: 1 , silts and mud; 2 , silty sands and mixed sediments; 3 , sands and gravel ${ }_{i}$

- coast exposure and water activity [EXPOS, coded] $(0 \text {, sheltered; } 1 \text {, mixed; } 2 \text {, exposed })_{i}$

- presence of macroalgae in the biotope [ALGAE, coded] (0/1);

- total abundance of harpacticoids [ $\lg N, \log$ ind. 10 $\mathrm{cm}^{-2}$ ];

- annually averaged chlorophyll a (chl a) concentration at the water surface $\left(C H L A, \mathrm{mg} \mathrm{m}^{-3}\right)$, retrieved from SeaWiFS satellite remote sensing (1997-2005), source: World Ocean Atlas 2005 (WOA05), www. nodc.noaa.gov/OC5/WOA05/pr_woa05.html;

- annual net primary production based on the standard vertically generalized production model algorithm [NPP, mg C m$\left.{ }^{-2} \mathrm{yr}^{-1}\right]$, source: OceanColor Web, http://oceancolor.gsfc.nasa.gov/;

- organic matter flux to the bottom [CFLUX, mg C $\left.\mathrm{m}^{-2} \mathrm{yr}^{-1}\right]$, calculated according to Udalov et al. (2005). 
In addition, several attributes of the sampling procedures were used:

- sample size [SAMPLE, $\left.\log \mathrm{cm}^{2}\right]_{i}$

- sampling effort [EFFORT, log $\mathrm{cm}^{2}$ ] (total sampled area $=$ Sample size $\times$ Number of samples);

- sieve mesh size used [SIEVE, $\mu \mathrm{m}]$, and if harpacticoids were picked up without sieving, a minimal value of $20 \mu \mathrm{m}$ was assigned;

- sampling time range [TIME_RANGE, months] (number of months per year when samples were collected).

In addition, 2 binary 'dummy' variables were used: one for hemispheres (HEMI $=0$ for southern and 1 for northern datasets); and another (COAST) equals 0 for open coasts and 1 for enclosed seas. We also use the interaction term $H E M I \times L A T$ to check the possible difference in the slopes of latitudinal trends.

\section{Diversity estimations}

While the concept of diversity components has been widely used for a long time, there is no agreement regarding how these components should be defined and measured. Several attempts have been made to tie $\alpha$ and $\gamma$ diversity to specific spatial scales (reviewed by Gray 2000 and Whittaker et al. 2001, see also Azovsky 2011), but little consensus has emerged on this point. The plethora of terms and formulas continues to impede objective comparisons between studies and therefore complicates the generalization of patterns and determinants of diversity. Here, we follow the utilitarian approach, identifying $\gamma$ diversity as the total number of species observed in a given dataset, regardless of its area; $\alpha$ diversity as the mean species number in a standardized sampling unit (averaged across all such units in a dataset); and $\beta$ diversity as the rate of species accumulation from point to point (between sampling units).

Diversity estimates are highly sensitive to sampling effort and the density of individuals. These pitfalls can be largely avoided by using species accumulation curves (SACs), which may be based on either individuals or samples. This approach allows for meaningful standardization and comparison of datasets (Gotelli \& Colwell 2001). These curves were constructed for each dataset (if they were not presented in the original publication) by rarefaction, i.e. calculating the average number of species accumulated over all pairs of samples, all triplicates, etc. In a few cases when only incomplete data were available (e.g. number of species per sample, in a subset of samples and in a total set were given), the SAC was inter- polated by linear approximation in double log space (Azovsky 2011).

\section{$\alpha$ diversity}

We used 2 standardized $\alpha$ diversity measures. The first was the number of species $(S)$ per $10 \mathrm{~cm}^{2}$, which is the conventional sample size for meiobenthic studies. If the sample size for a given dataset differed from $10 \mathrm{~cm}^{2}$, the $S$ value was derived from the respective SAC. Second, we used the expected number of species per 100 individuals, ES(100), estimated from species abundance data using PRIMER6 software (Clarke \& Gorley 2006). Both measures were decimal-logarithmically transformed for further analysis.

\section{$\beta$ diversity}

$\beta$ diversity can be defined and estimated in many different ways. Any simple partitioning of the total $\gamma$ richness into $\alpha$ and $\beta$ components, either in an additive $(\beta=\gamma-\alpha)$ or multiplicative $(\beta=\gamma / \alpha)$ way, is strongly sampling dependent (Koleff et al. 2003b) and, thus, inappropriate in our case. Dissimilarity-

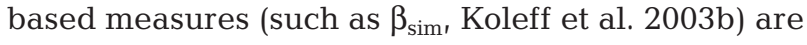
independent of differences in sample size, but they require primary sample-based species data, which are not always available from published papers. Therefore, we quantified $\beta$ diversity as the slope of the sample-based SAC (in double log-log space), as first proposed by Cody (1975) (see also Ricotta et al. 2002, Azovsky 2011). Unlike many other indices, this method appears to be rather independent of the sample size and sampling effort. The test of linearity was performed before interpolation, and only the strictly linear (with $\mathrm{r}^{2}>0.95$ in double log axes) SAC plots or their initial segments were used for interpolation.

\section{Statistical analysis}

To test for bathymetric and latitudinal changes in harpacticoid diversity, a 1-way analysis of variance (ANOVA) was carried out for $\alpha$ and $\beta$ diversity measures separately, using sampling depth or latitude as random factors. A forward stepwise multiple regression procedure (with an entering $\alpha$ value of 0.05 ) was performed to retain those variables that contributed significantly to the model using SYSTAT10 software (SPSS). This software was also used to compute ordi- 
nary, multiple, and partial linear correlations. To check whether the different subsets of data deviated systematically from the general trend, we performed the group comparison test for residuals (Neter et al. 1996). For every appropriate regression model, Student's $t$-test was used to compare the residuals for (1) Northern against Southern hemisphere locations, and (2) enclosed seas (White, Baltic, Black, Caspian, and Mediterranean Seas) against the open ocean locations. To estimate the relative contributions of $\alpha$ and $\beta$ diversity to determining species richness, we calculated the partial correlations between both diversity components and the total number of species found at a site.

\section{RESULTS}

\section{Interrelationships between explanatory variables}

First, we checked the explanatory variables for potential multicollinearity, which could distort the results of a multiple linear regression. A pairwise correlation test was performed with Bonferroni correction for multiple comparisons (Table 1).

None of the variables was correlated with latitude or organic flux, so these 2 parameters could be further used as independent predictors of diversity. Against expectations, the total abundance was not correlated with CFLUX but was highly correlated with depth and sieve size. The following 'best fit' regression was obtained: $\lg N=2.49-6.59$ SIEVE $0.35 \lg D E P T H\left(\mathrm{n}=90, \mathrm{R}^{2}=0.580\right)$. Thus, the residuals from this regression (referred to as $\lg N_{\text {corr }}$ ) were used hereinafter to study the pure effect of abundance corrected for depth and the sieve size used. Addition-

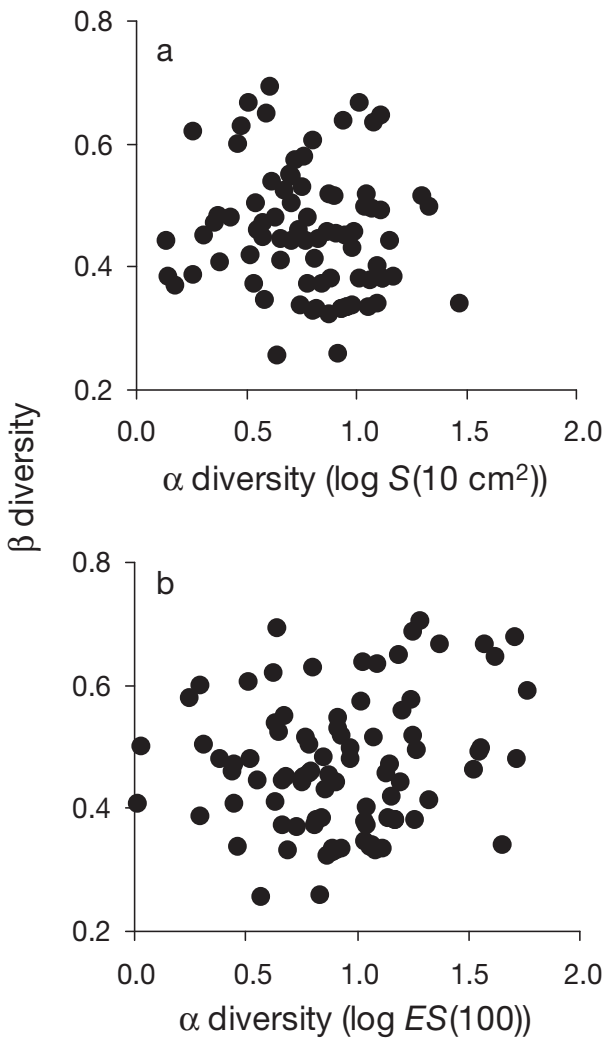

Fig. 3. Relationship between $\beta$ diversity and (a) number of species per $10 \mathrm{~cm}^{2}, S_{\text {; }}$ (b) expected number of species per 100 individuals, $E S(100)$

ally, the type of sediment was weakly but significantly correlated with shore exposure, and both were correlated with depth. This reflects the obvious fact that highly exposed, sandy sediments mainly occur in shallow waters. Therefore, in performing the regression analysis, these variables were included in the final models separately.

Table 1. Pairwise correlation between the explanatory variables (Pearson's r). Only variables selected in the final regression models are presented. TIME_RANGE: sampling time range (months), $\lg D E P T H$ : depth (log m), SEDIM: sediment properties, SIEVE: sieve mesh size $(\mu \mathrm{m}), S P A T \_R A N G E$ : spatial extent of the study $(\log \mathrm{km}), D E P T H \_R A N G E$ : depth range between the shallowest and deepest sampling points $(\log \mathrm{m}), \lg N$ : total abundance of harpacticoids (log ind. $10 \mathrm{~cm}^{-2}$ ), CFLUX: organic matter flux to the bottom ( $\left.\mathrm{mg} \mathrm{C} \mathrm{m}{ }^{-2} \mathrm{yr}^{-1}\right)$. Bonferroni-corrected significance level: ${ }^{*} \mathrm{p}<0.05,{ }^{* *} \mathrm{p}<0.01$

\begin{tabular}{|lrcccccc|}
\hline & LAT & $\begin{array}{c}\text { TIME_ } \\
\text { RANGE }\end{array}$ & $\lg$ DEPTH & SEDIM & SIEVE & $\begin{array}{c}\text { SPAT_ } \\
\text { RANGE }\end{array}$ & $\begin{array}{c}\text { DEPTH_ } \\
\text { RANGE }\end{array}$ \\
\hline TIME_RANGE & 0.052 & & & & & \\
lgDEPTH & -0.192 & -0.219 & & & & \\
SEDIM & 0.092 & 0.076 & $-0.406^{* *}$ & & & \\
SIEVE & 0.012 & -0.131 & 0.001 & -0.084 & & \\
SPAT_RANGE & -0.262 & -0.105 & $0.410^{* *}$ & -0.249 & -0.039 & & \\
DEPTH_RANGE & -0.173 & -0.214 & $0.819^{* *}$ & $-0.335^{*}$ & -0.035 & $0.446^{* *}$ & -0.225 \\
lgN & 0.033 & 0.077 & $-0.555^{* *}$ & 0.201 & $-0.538^{* *}$ & -0.154 & -0.129 \\
CFLUX & 0.241 & 0.021 & 0.175 & 0.078 & -0.129 & 0.309 & 0.253 \\
\hline
\end{tabular}



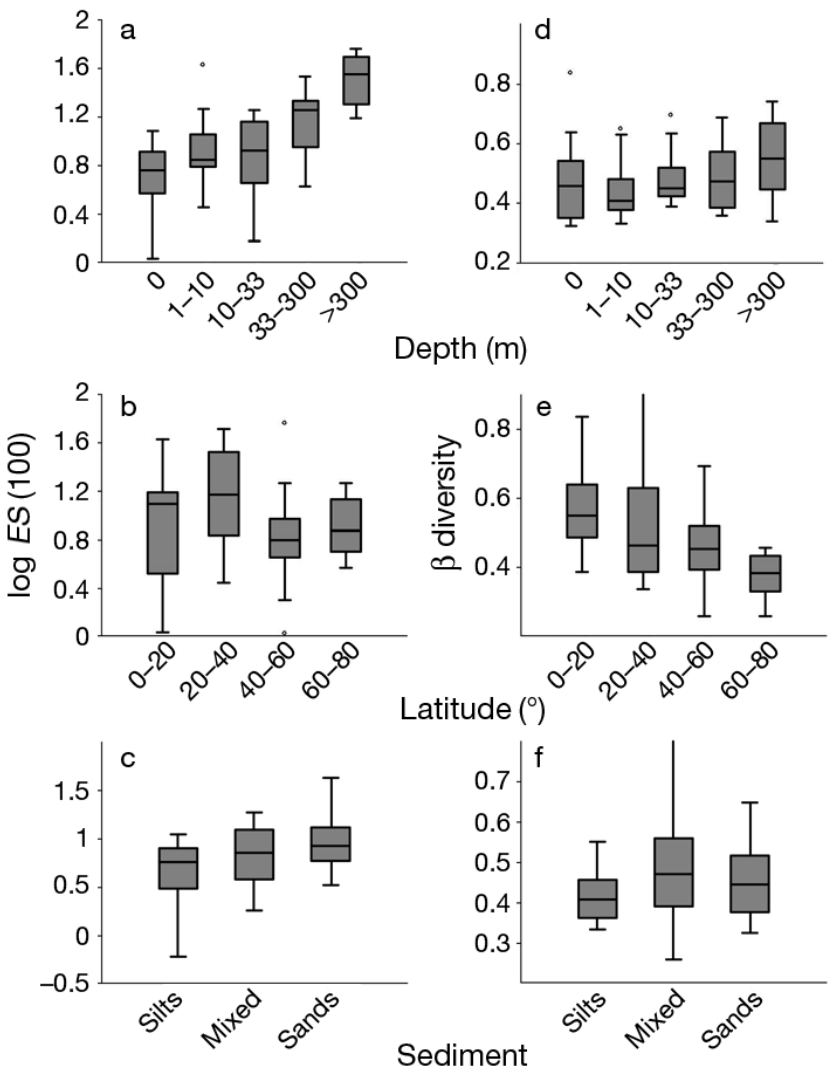

Fig. 4. Values of $(\mathrm{a}-\mathrm{c})$ expected number of species per 100 individuals, $E S(100)$, and (d-f) $\beta$ diversity, averaged by $(\mathrm{a}, \mathrm{d})$ depth ranges, $(b, e)$ latitude bands, and $(\mathrm{c}, \mathrm{f})$ types of sediment for depths 0 to $300 \mathrm{~m}$. Line: median; box: interquartile range; whiskers: 5 th-95th percentile; dots: outliers

\section{Patterns in diversity: univariate analysis}

The $2 \alpha$ diversity measures were highly correlated ( $\left.\mathrm{r}=0.642, \mathrm{p}<10^{-7}\right)$, and neither $S$ nor $E S(100)$ showed a correlation with $\beta$ diversity (Fig. 3). Thus, the 2 diversity components varied from site to site independently and should therefore be driven by different sets of factors. Indeed, 1-way ANOVA showed that $\alpha$ diversity (as $E S(100))$ increased with depth $(F=16.81$, $\left.\mathrm{p}<10^{-6}\right)$ but did not change with latitude $(F=1.13, \mathrm{p}=$ 0.347; Fig. $4 \mathrm{a}, \mathrm{b})$. In contrast, $\beta$ diversity presented an evidently decreasing latitudinal $(F=5.62, \mathrm{p}=0.0013)$ but not a bathymetric trend $(F=1.86, \mathrm{p}=0.124$; Fig. 4d,e). In shallow waters, the values for both diversity components were slightly higher for mixed sediments and sands than on silts, although the differences were statistically insignificant (Fig. 4c,f).

\section{Multiple regression analysis: $\alpha$ diversity}

For all of the data from the subtidal zone and deeper, step-wise regression analysis yielded the fol- lowing results (Table 2, Models 1 and 2). The last 2 terms in these equations can be re-written as follows: $\ldots+0.0002 C F L U X \times(\lg D E P T H-1.5)$ for $\lg S$; or $\ldots$ +0.0002 CFLUX $\times(\lg D E P T H-2)$ for $\lg E S(100)$.

Thus, both $\alpha$ diversity measures depended on the productivity in the overlying water column. This effect of the food supply was, in turn, depth dependent, i.e. it was negative in the shallowest zone (up to 30 to $100 \mathrm{~m}$ ), but positive in deeper waters. In addition, $E S(100)$ increased with depth. Thus, in deeper areas, the harpacticoid fauna was potentially richer but more strongly resource limited. Richness per area depended strongly on both total abundance and the size of the sieve used. Both effects increased noticeably with depth. The regressions (Table 2, Models 7, 3, and 5) predict that, as an example, using the $32 \mu \mathrm{m}$ instead of $63 \mu \mathrm{m}$ mesh size should yield on average 12 to $16 \%$ more species in the shallowest habitats, but up to a $34 \%$ increase in the deep sea areas.

To differentiate between the effects of depth and food supply on $\alpha$ diversity, we performed the analysis for the shallow and deep water datasets separately. For the upper subtidal zone up to $33 \mathrm{~m}$, the following regressions were obtained (Table 2, Models 3 and 4). The effect of organic flux was negative in this depth range, especially in highly productive areas. Surprisingly, both measures were negatively correlated with the time range of the sampling session. Additionally, $E S(100)$ was higher for sands than on silts, and the richness per area again depended on average abundance and sieve size.

Deeper than $33 \mathrm{~m}$, the richness per area correlated only with average abundance and sieve size, which explained over $90 \%$ of its total variance (Table 2, Model 5). In contrast, the ES(100) values increased with depth and with the level of organic flux, with the effect of the latter variable becoming stronger as depth increased, and Model 6 can be re-written as: $\lg E S(100)=0.208+0.3 .61 \lg D E P T H+0.0051 C F L U X$ $\times(\lg D E P T H-1.27)$. Because we could not estimate productivity for the littoral zone, these terms were not included in the model. For the intertidal data, we obtained the following results (Table 2, Models 7 and 8). Both $\alpha$ diversity measures correlated negatively with the time range. The richness per area increased with total abundance and decreased with sieve size, as was found previously. In contrast, $E S(100)$ decreased as total abundance increased. It should be noted that multiple regression analysis also failed to detect either latitudinal trends or significant differences between hemispheres for $\alpha$ diversity. 


\section{Multiple regression analysis: $\beta$ diversity}

The set of significant predictors retained for $\beta$ diversity differed from that for $\alpha$ diversity. In the intertidal zone (Table 2, Model 9), $\beta$ diversity showed a significant latitudinal trend, decreasing polewards. It was also positively correlated with the spatial range of the survey and increased with respect to sediment composition from silts to sands. In the subtidal zone and deeper, both spatial scale dimensions (horizontal $S P A T \_R A N G E$ and vertical DEPTH_RANGE) were significant, as was latitude (Model 10). Moreover, in the upper sublitoral zone (Model 11), the effect of scale also increased at low latitudes. The last terms of the model can be re-written as $\ldots+0.087 \lg S P A T_{-}$ RANGE $\times(73-L A T)$. According to the model, a 10-fold expansion of the spatial range yields an approximately $20 \%$ increase in $\beta$ diversity near the equator but has almost no effect in subpolar areas. In other words, diversity increased with an expanding spatial scale much faster in the tropics than in the polar seas.

For the deepest datasets, latitude and depth range were the only significant variables (Model 12). Thus, the latitudinal trend was expressed at all depths but was much more pronounced in shallow waters, where latitude explained up to half of the variation in $\beta$ diversity (Fig. 5).

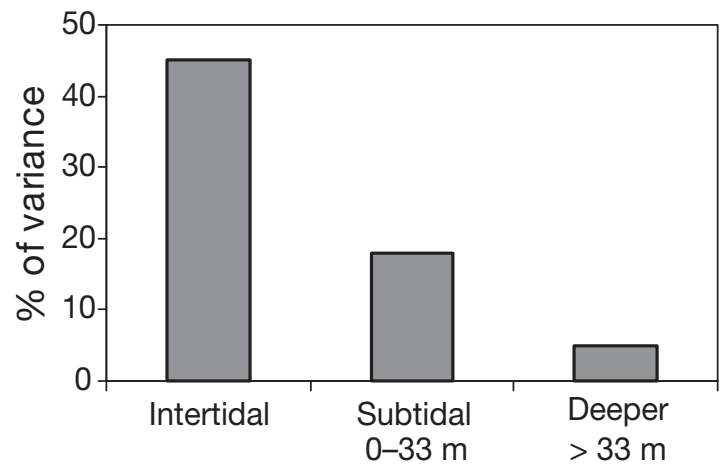

Fig. 5. Percentage of $\beta$ diversity variance explained by latitude at different depths

\section{Group comparison tests}

For every appropriate regression model, the group comparison test was performed to compare the residuals for (1) Northern against Southern hemisphere locations, and (2) enclosed seas against the open ocean locations. No significant differences in residual values were found, either between hemispheres or between enclosed and open habitats. None of the respective dummy variables $(H E M I, H E M I \times L A T$, $C O A S T$ ) were significant. Thus these subsets of data did not deviate systematically from the general trends.

Table 2. Final regression models for $\alpha$ and $\beta$ diversity. Only significant terms are presented. $R^{2}$ : adjusted squared correlation; n: number of cases; $L A T$ : absolute latitude (degrees); $\lg N_{\text {corr }}$ : residuals for best-fit regression of $\lg N_{i}$ other terms as in Table 1

\begin{tabular}{|c|c|c|c|c|}
\hline No. & Depth range, $\mathrm{m}$ & Regression model & $\mathrm{R}^{2}$ & $\mathrm{n}$ \\
\hline \multicolumn{5}{|c|}{$\alpha$ diversity } \\
\hline 1 & $1-5623$ & $\begin{array}{l}\lg S=0.139+0.372 \lg N_{\text {corr }}-3.387 \text { SIEVE }-0.0003 \text { CFLUX } \\
+0.0002 \text { CFLUX } \times \lg D E P T H\end{array}$ & 0.585 & 50 \\
\hline 2 & $1-5623$ & $\begin{array}{l}\lg E S(100)=0.940+0.119 \lg D E P T H-0.0004 C F L U X \\
+0.0002 \text { CFLUX } \times \lg D E P T H\end{array}$ & 0.596 & 57 \\
\hline 3 & $1-33$ & $\begin{array}{l}\lg S=0.353+0.302 \lg N_{\text {corr }}-2.109 \text { SIEVE }-0.021 \text { TIME_RANGE } \\
-0.0001 \text { CFLUX }\end{array}$ & 0.536 & 37 \\
\hline 4 & $1-33$ & $\begin{array}{l}\lg E S(100)=0.892-0.025 \text { TIME_RANGE }+0.189 \text { SEDIM } \\
-0.0006 \text { CFLUX + 0.000001 CFLUX }\end{array}$ & 0.647 & 38 \\
\hline 5 & $33-5623$ & $\lg S=-1.039+0.899 \lg N_{\text {corr }}-4.143$ SIEVE & 0.935 & 13 \\
\hline 6 & $33-5623$ & $\begin{array}{l}\lg E S(100)=0.208+0.361 \lg D E P T H-0.0065 C F L U X \\
+0.0051 C F L U X \times \lg D E P T H\end{array}$ & 0.723 & 19 \\
\hline 7 & 0 & $\lg S=0.851-0.027$ TIME_RANGE $+0.073 \lg N_{\text {corr }}-1.623$ SIEVE & 0.436 & 26 \\
\hline 8 & 0 & $\lg E S(100)=1.598-0.031$ TIME_RANGE $-0.263 \lg N_{\text {corr }}$ & 0.471 & 27 \\
\hline \multicolumn{4}{|c|}{$\beta$ diversity } & 38 \\
\hline 10 & $1-5623$ & $\begin{aligned} \beta & =0.465-0.0013 \text { LAT }+0.026 \lg S P A T_{-} R A N G E \\
& +0.035 \lg D E P T H \_R A N G E\end{aligned}$ & 0.51 & 63 \\
\hline 11 & $1-33$ & $\begin{array}{l}\beta=0.498-0.0013 L A T+0.087 \lg S P A T_{-} R A N G E \\
\quad-0.0012 L A T \times \lg S P A T_{-} R A N G E\end{array}$ & 0.643 & 38 \\
\hline 12 & $33-5623$ & $\beta=0.454-0.0026 L A T+0.084 \lg D E P T H \_R A N G E$ & 0.583 & 23 \\
\hline
\end{tabular}




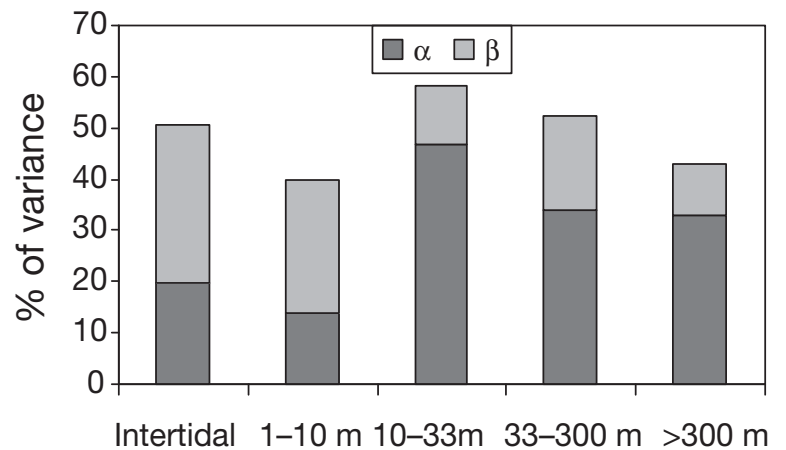

Fig. 6. Relative contribution of $\alpha$ diversity as the expected number of species per 100 individuals, ES(100) and $\beta$ diversity to between-site differences in total species richness at different depths

\section{Relative role of $\alpha$ and $\beta$ components}

Squared partial correlations between $\alpha$ and $\beta$ diversity and the total number of species found at a site were used to estimate their relative contributions to determining the total species richness. The results for different depth zones are shown in Fig. 6. Variations in $\beta$ diversity were more important in shallow waters (intertidal and upper sublittoral zone), while in deeper waters, variations in the $\alpha$ component played the main role. It should be noted that a significant part of the total variance remained unexplained by either the $\alpha$ or $\beta$ component. This part was related to differences in sampling effort (which ranged over 4 orders of magnitude in our data).

\section{DISCUSSION}

Our results show that the $\alpha$ and $\beta$ components of harpacticoid diversity change from site to site independently and are correlated with different sets of predictors.

\section{Diversity measures: methodological aspects}

Neither diversity measure correlated significantly with either sample size or sampling effort, indicating their robustness regardless of sampling procedures. There was, however, a difference between 2 measures of $\alpha$ diversity, viz. richness per unit area (species density, $S$ ) and expected richness per 100 individuals, $E S(100)$. The 2 measures, although widely used in quantitative benthic studies, may produce very different results, and it is not always clear which measure of diversity is more appropriate
(Gotelli \& Colwell 2001). In our case, species density (to be more precise, its logarithm, lg $S$ ) was strongly correlated with $\log$ abundance $(\mathrm{R}=0.473, \mathrm{p}=$ 0.00005): the more harpacticoids that inhabit a unit area (and, thus, are sampled and counted), the more species can be found. Additionally, unlike ES(100), the species density depends on the mesh size used: the use of a coarse sieve yields significantly fewer species $(\mathrm{R}=-0.391, \mathrm{p}=0.002)$. The effect of mesh size becomes noticeably stronger with increasing depth, indirectly indicating the changes in size structure of harpacticoid assemblages. Waterdepth-related decrease in meiobenthic size is welldocumented (Udalov et al. 2005, Mokievsky et al. 2007), but the effects of mesh size on estimates of meiofaunal diversity have rarely been examined. Several authors have argued that the main contribution of smaller mesh sizes is the retention of more individuals rather than more species (Rodrigues et al. 2007). Leduc et al. (2010), however, found that, at a south-west Pacific bathyal site, the $63 \mu \mathrm{m}$ mesh yielded significantly lower nematode diversity estimates than the finer meshes. Our analysis also shows that using a coarser mesh leads to significantly lower harpacticoid abundance and diversity estimates, especially at deep-sea sites, which probably have more small-sized species. However, the effect is only significant for total species number $S$, while $E S(100)$ is the more robust estimator in this respect. Thus, the latter diversity measure is less sensitive to the sampling effort and the sample processing procedure employed, so it is more appropriate in comparative studies, as has been mentioned earlier (Gotelli \& Colwell 2001).

Veit-Köhler et al. (2010) recently provided an analysis of an extensive sample-based dataset for European shallow-water harpacticoid communities, using the species number per sample as an $\alpha$ diversity estimator. As expected, the number of individuals and sampled area were found to be the main predictors of local species richness, along with water depth. No attempts were made to standardize the richness values to sampling effort, so these results do not allow drawing conclusions about the significance of bathymetric or latitudinal trends.

\section{$\alpha$ diversity patterns}

$\alpha$ diversity primarily depends on the flux of organic matter to the sediments, except in the intertidal zone where such flux cannot be calculated. The effect of CFLUX is depth-dependent (the regressions include 
significant interaction terms). This effect is strongly negative in the shallowest waters, subsides in the lower sublittoral zone $(33-100 \mathrm{~m})$, and becomes increasingly positive deeper. Thus, the interplay between depth, food supply, and $\alpha$ diversity appears to be rather complex and non-linear, but generally fits the hump-shaped 'diversity-productivity' model.

High primary productivity in near-shore waters tends to promote high biomass but low species richness (Snelgrove et al. 2000). In these areas, communities tend to be dominated by a small number of species that are able to monopolize resources. For example, in a large-scale study, Rombouts et al. (2009) found a significant inverse relationship of marine epipelagic $(0-200 \mathrm{~m})$ copepod diversity with chl a content, indicating that diversity is high in oligotrophic regions. There are a number of hypotheses to explain the 'decrease phase' of the diversity-productivity relationship, and some of these hypotheses are applicable to marine meiofauna (see Rosenzweig 1995, Levin et al. 2001 for a review).

There is some additional, though indirect, evidence for negative effects of productivity in the intertidal and subtidal zones. A positive relationship between total meiofaunal abundance and the input of organic matter has been reported repeatedly (De Troch et al. 2006, Mokievsky et al. 2007, Lampadariou et al. 2009). Thus, the total abundance could be treated (under some reservations) as a proxy for the available food supply. In this case, the negative correlation between $E S(100)$ and abundance in the intertidal zone can also reflect the inverse relationship between shallow-water richness and the food supply. This negative effect of organic inputs is also indirectly confirmed by the fact that higher diversity is observed in sands than in silts and muds. In silty muds, the dry weight of organic matter can reach $10 \%$ of a sample, while for sandy shores, this value is usually $<1 \%$ (Giere 2009).

It should be taken into consideration that the available food supply may be strongly underestimated for the upper subtidal zone for several reasons. First, the empirical regressions used for flux estimations are less accurate at shallow depths (Buesseler \& Boyd 2009). Second, these estimations leave out the lateral organic input from coastal outflows. Third, they do not include the production of macrophytes and especially of benthic microalgae and bacteria, as the main source of food for many harpacticoids. Therefore, the actual food supply in the shallowest waters could be even higher than the values used in our study, shifting these localities further towards the 'descending' part of the hump-shaped diversity-productivity curve.
Deeper, in the lower shelf, continental slope, and abyssal regions, our data show a reversal of the sign in the diversity-productivity relationship, which becomes positive because of a low level of food supply. This positive effect becomes stronger as depth increases and food limitation strengthens.

A positive link with productivity has often been considered as the major cause of deep-sea diversity patterns, although the direct evidence for this is currently scarce and ambiguous (Levin et al. 2001). Tietjen (1989) and Lambshead et al. (2002) reported positive associations of deep-sea nematode richness with the presumed (but unmeasured) levels of seafloor POC fluxes in the northwest Atlantic and central equatorial Pacific, respectively. For abyssal Harpacticoida from the Angola Basin, Rose et al. (2005) observed a higher diversity at a site with higher sediment organic content, as a proxy of the overlying productivity. Gambi et al. (2010) summarized data on meiofaunal diversity from the deep Mediterranean Sea at depths ranging from 200 to $4617 \mathrm{~m}$ and reported that the quality and quantity of food sources explained the greatest proportion of the variance of meiofaunal diversity, and the importance of food sources increased with increasing depth.

Along with the depth-related effect of productivity, our regressions for $\alpha$ diversity also include depth per se as an independent term (Table 2, Models 1, 2, and 6 ), indicating the existence of some other depthrelated factor(s) that increases richness. Other conditions being equal, the deepest samples are more species-rich than the shallowest ones, resulting in the overall positive bathymetric trend in $\alpha$ diversity (Fig. 4a). Similar trends have been repeatedly reported for various taxa. Indeed, when comparisons are controlled for spatial scale, geography, taxonomy, sampling methods, and habitat, the number of macrobenthic species coexisting at small scales in the deep sea is considerably higher than in shallowwater communities, while their numerical abundance is usually low (McClain et al. 2009). Nematode $\alpha$ diversity also increases with water depth, being highest in the bathyal zone (Lambshead \& Boucher 2003). For harpacticoids, recent studies have confirmed higher diversity in the deep sea than in shallow marine habitats (Thistle 2001, Seifried 2004, Rose et al. 2005, Miljutin et al. 2010). Veit-Köhler et al. (2010) reported a positive effect of depth on shelf harpacticoid richness for 2 of 3 regions.

The interplay between depth per se and food supply, revealed by our regression models, could theoretically result in a unimodal bathymetric pattern 
similar to these reported for both macrobenthos and meiobenthos (see 'Introduction'). However, we did not find such unimodality with abyssal descent for harpacticoids. One possible reason for this is that harpacticoids are unusually successful in the deep sea as compared to macrofauna (Thistle 2001). This fact could also be explained by the small number (4) of data points available from the abyssal zone.

Surprisingly, both $\alpha$ diversity measures were negatively correlated with the time range of the sampling session. Presumably, this is because the long-term, year-round studies usually covered seasons of unfavorable conditions. In these periods, the abundance of some species drops below detectable levels, and mean species richness therefore decreases. Indeed, this effect is significant only in the intertidal and upper subtidal zones, where the seasonality is expressed more clearly. The type of sediment was only significant for the upper subtidal zone, with sandy sediments exhibiting higher richness than silts (see next subsection).

\section{$\beta$ diversity patterns}

According to our results, $\beta$ diversity, in contrast to $\alpha$ diversity, shows no correlation with total harpacticoid abundance or primary productivity but instead depends strongly on both horizontal and vertical dimensions of spatial scale. This diversity component is commonly suggested to be mediated by the nature and degree of habitat heterogeneity, which increases with spatial scale due to patchiness, metapopulation dynamics, and/or environmental gradients (Willig et al. 2003, Veech \& Crist 2007). Indeed, a positive correlation between $\beta$ diversity and scale has been found for birds and mammals (Koleff \& Gaston 2002, Melo et al. 2009), Mediterranean macrofauna (Munari \& Mistri 2008), deep-sea nematodes (Danovaro et al. 2009), and cladoceran zooplankton (Declerck et al. 2011). Intertidal harpacticoids present a noticeable increase in $\beta$ diversity when the spatial scale increases from centimeters to tens of meters (Azovsky et al. 2004, Rose \& Seifried 2006). For Antarctic macrofauna, habitat heterogeneity has a strong influence on $\beta$ diversity at a wide range of scales up to $290 \mathrm{~km}$, while the effects of productivity are low and are significant only at the largest scales (Thrush et al. 2010). Our analysis corroborates the scale-dependence of $\beta$ diversity, therefore suggesting environmental heterogeneity as the most important generator of this diversity component for benthic harpacticoids. $\beta$ diversity demonstrates a clear latitudinal trend, decreasing polewards (i.e. low-latitude communities are patchier than polar ones when considered at comparable scales). Moreover, the strength of this gradient is clearly scale-dependent, increasing with spatial scale. Causes of this latitudinal gradient are less obvious. Various explanatory mechanisms have been proposed, but no single explanation is generally accepted. As only $\beta$ diversity shows such a latitudinal trend for harpacticoids, we hypothesize that this trend most likely reflects geographic variations in environmental heterogeneity, rather than variations in primary productivity. This hypothesis provides an explanation for the fact that the effect of spatial scale is also greater at low latitudes. If environmental heterogeneity actually decreased polewards for meiofauna, one could expect it (and, thus, $\beta$ diversity) to increase much more rapidly with expanding scale in the tropics than in polar seas. Qian \& Ricklefs (2007) studied the relationship between spatial scale and $\beta$ diversity for North American vascular plants and similarly found that the effect of scale increased with latitude. They attributed this pattern to the increased environmental variability at lower latitudes. For shallowwater sessile macrofauna, the latitudinal gradient of $\beta$ diversity has also been found to strongly contribute to the gradient of $\gamma$ diversity, whereas local $\alpha$ diversity does not show a clear latitudinal pattern (Clarke \& Lidgard 2000, Okuda et al. 2004a,b). Danovaro et al. (2009) also reported the highest rates of species turnover for the widest depth range and geographical distances, and considered the turnover diversity to be crucial for a predictive understanding of the spatial patterns of deep-sea nematode assemblages.

In the littoral zone, $\beta$ diversity is lower on average for silts than for sands and especially for mixed heterogeneous sediments (Fig. 4f). A similar pattern was obtained for $\alpha$ diversity (Fig. 4c). While many harpacticoids are known to differ in their granulometric preferences (Giere 2009), comparative data on diversity from different sediments are scarce and controversial. Some authors have reported higher diversity for sands than silts (e.g. Hartzband \& Hummon 1974, Coull \& Dudley 1985, Rybnikov et al. 2003), but others have suggested the opposite trend (Chertoprud et al. 2009). The effect of sediment type (if significant) could be attributed to the higher physical heterogeneity of sites with mixed sediments compared to pure silts or muds. In any case, the overall effect of this granulometry factor is less important compared to the effects of other factors. 


\section{Relative role of diversity components}

The relationships described can be summarized in the following conceptual model (Fig. 7). Food supply (estimated as the organic matter flux from overlying waters) is the main driving factor for $\alpha$ diversity, and depth acts as a controlling co-variable affecting the form and strength of the relationship. Environmental heterogeneity is the main driving factor for $\beta$ diversity, and latitude acts as a controlling co-variable affecting the strength of this relationship.

These variables together account for 50 to $70 \%$ of the overall diversity variance, which is sufficient to treat them as the primary factors determining the general diversity pattern at a global scale. The remaining variance could be attributed to local (biotic and environmental) factors neglected in our analysis as well as to possible inaccuracy of the data. With respect to the total number of species found at a site, the $\alpha$ and $\beta$ diversity components together explain slightly more than half of its variance across the whole dataset (multiple $\mathrm{R}^{2}=0.526$ for $E S(100)$ and $\beta$ as covariates). The unexplained remainder is related to differences in sampling effort, indicating the great importance of this parameter for local richness estimations.

Latitude and depth are not themselves direct drivers of diversity patterns. They merely correspond to the complex geographic gradients associated with (and even influence the effects of) other environmental factors, such as temperature, trophic conditions, environmental stability, or habitat heterogeneity

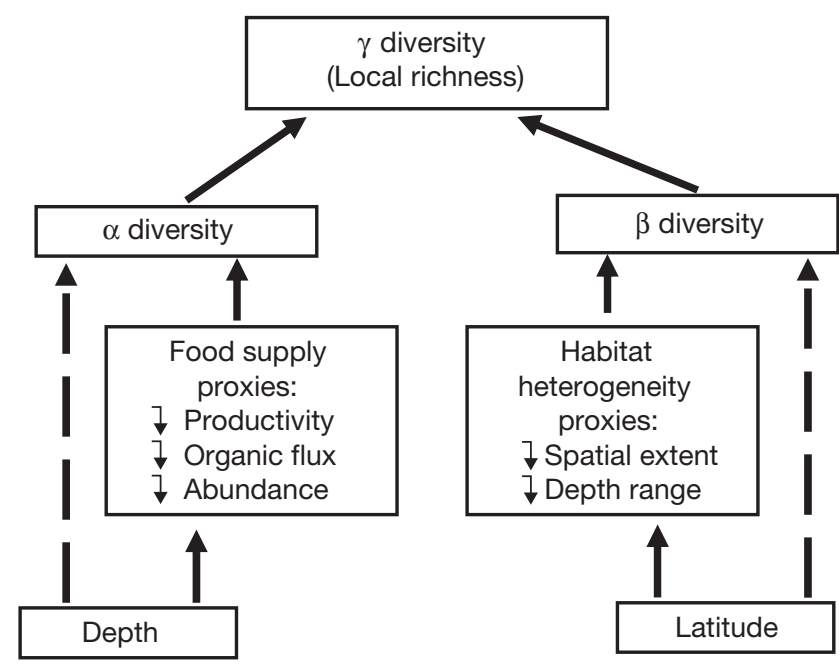

Fig. 7. Principal relationships between causal factors (solid lines) and correlated factors (dashed lines) of the diversity components
(Hawkins \& Giniz-Filho 2004, Udalov et al. 2005). The dashed arrows in the diagram (Fig. 7) indicate these correlative (not causal) relationships.

Thus, $\alpha$ and $\beta$ diversities act as independent (and spatially uncorrelated) components of overall regional diversity ( $\gamma$ diversity) that are driven by different mechanisms. According to our results, spatial heterogeneity (which influences $\beta$ diversity) is the main structure-forming factor in the diverse and variable environment of the shallowest waters. Deeper, this role shifts to trophic conditions and, thus, to $\alpha$ diversity, which mainly contributes here to the total variance in $\gamma$ diversity (Fig. 6). Latitudinal gradient is also most pronounced in the intertidal zone, where it explains up to half of the variation in $\beta$ diversity (Fig. 5). In the shallowest subtidal zone and even deeper, where geographical changes, such as solar energy or temperature, are less pronounced, this trend is weaker, but still significant.

Our results are consistent with those from other studies on meiofaunal diversity. Several inter-regional comparisons of nematode $\alpha$ diversity, using various diversity indices, found no obvious latitudinal trends, in contrast to macrofauna (Vanhove et al. 1999, Mokievsky \& Azovsky 2002, Muthumbi et al. 2004). Changes in deep-sea nematode assemblages along bathymetrical gradients prevail over latitudinal gradients (Rex et al. 2001 and references therein, Fonseca et al. 2010). The results of a deepsea Mediterranean meiofauna analysis (Gambi et al. 2010) suggested that the observed richness variability was explained mainly by the geographical position of the sampling sites (latitude and longitude, cumulatively $42 \%$ ) at 200 to $1000 \mathrm{~m}$ depths, whereas deeper (>2000 m), food sources explained $37 \%$ of the variance. As Mokievsky \& Azovsky (2002) demonstrated using a large-scale dataset, the nematode species richness in a biotope (or $\alpha$ diversity) is approximately twice as high in the deep sea (deeper than $400 \mathrm{~m}$ ), while the main source of diversity in shallow waters is high species turnover ( $\beta$ diversity) due to the heterogeneity of biotopes. Nematodes from the equatorial central Pacific also show higher regional diversity in coastal waters due to high species turnover, despite lower sample diversity in coastal waters than in the deep sea (Lambshead \& Boucher 2003).

Whereas the present study is correlation-based and does not prove specific mechanisms responsible for generation or maintenance of meiofaunal diversity, the patterns observed may aid in further validation or refutation of some prevailing hypotheses regarding these mechanisms. These findings may 
also shed some light on the 'latitude or depth' discussion related to the leading gradients in meiofaunal diversity (Lambshead et al. 2000, Rex et al. 2001, Mokievsky \& Azovsky 2002). Both factors are important but affect different diversity components, and the relative importance of latitude drops but that of depth increases in the deepest areas. As a result, the observed diversity patterns in the shallowest (intertidal and upper subtidal) waters are mainly 'horizontally' structured, in both respects of spatial scale and latitude. In contrast, deep-sea communities are mainly vertically structured, with depth determining both components of their diversity patterns.

Acknowledgements. This research was supported by the Russian Foundation for Basis Research (Grant No. 09-0401151 and 12-04-00284). We thank 4 reviewers for comments that improved the manuscript.

\section{LITERATURE CITED}

Azovsky AI (2011) Species-area and species-sampling effort relationships: disentangling the effects. Ecography 34: $18-30$

Azovsky AI, Chertoprood ES, Saburova MA, Polikarpov IG (2004) Spatio-temporal variability of micro- and meiobenthic communities in the White Sea intertidal sandflat. Estuar Coast Shelf Sci 60:663-671

Baguley JG, Montagna PA, Lee W, Hyde LJ, Rowe GT (2006) Spatial and bathymetric trends in Harpacticoida (Copepoda) community structure in the Northern Gulf of Mexico deep-sea. J Exp Mar Biol Ecol 330:327-341

Boucher G (1990) Pattern of nematode species diversity in temperate and tropical subtidal sediments. PSZN I: Mar Ecol 11:133-146

Buesseler KO, Boyd PW (2009) Shedding light on processes that control particle export and flux attenuation in the twilight zone of the open ocean. Limnol Oceanogr 54: 1210-1232

Chertoprud ES, Gómez S, Gheerardyn H (2009) Harpacticoida (Copepoda) fauna and the taxocene diversity of the South China Sea. Okeanologiya 49:488-498

> Chertoprud ES, Garlitska LA, Azovsky AI (2010) Largescale patterns in marine harpacticoid (Crustacea, Copepoda) diversity and distribution. Mar Biodivers 40: 301-315

> Chertoprud ES, Gheerardyn H, Gómez S (2011) Harpacticoida (Crustacea: Copepoda) of the South China Sea: faunistic and biogeographical analysis. Hydrobiologia 666:45-57

Clarke KR, Gorley RN (2006) PRIMER v6: user manual/tutorial. PRIMER-E, Plymouth

> Clarke A, Lidgard S (2000) Spatial patterns of diversity in the sea: bryozoan species richness in the North Atlantic. J Anim Ecol 69:799-814

Cody ML (1975) Towards a theory of continental species diversities: bird distributions over Mediterranean habitat gradients. In: Cody ML, Diamond JM (eds) Ecology and evolution of communities. Belknap Press, Cambridge, MA, p 214-257

Corliss BH, Brown CW, Sun X, Showers WJ (2009) Deep-sea benthic diversity linked to seasonality of pelagic productivity. Deep-Sea Res I 56:835-841

Coull BC, Dudley BW (1985) Dynamics of meiobenthic copepod populations: a long-term study (1973-1983). Mar Ecol Prog Ser 24:219-229

Culver SJ, Buzas MA (2000) Global latitudinal species diversity gradient in deep-sea benthic Foraminifera. DeepSea Res I 47:259-275

Danovaro R, Bianchelli S, Gambi C, Mea M, Zeppilli D (2009) $\alpha-, \beta-, \gamma-, \delta$ - and $\varepsilon$-diversity of deep-sea nematodes in canyons and open slopes of Northeast Atlantic and Mediterranean margins. Mar Ecol Prog Ser 396:197-209

> De Troch M, Van Gansbeke D, Vincx M (2006) Resource availability and meiofauna in sediment of tropical seagrass beds: local versus global trends. Mar Environ Res 61:59-73

Declerck SAJ, Coronel JS, Legendre P, Brendonck L (2011) Scale dependency of processes structuring metacommunities of cladocerans in temporary pools of High-Andes wetlands. Ecography 34:296-305

Fonseca G, Soltwedel T, Vanreusel A, Lindegarth M (2010) Variation in nematode assemblages over multiple spatial scales and environmental conditions in Arctic deep seas. Prog Oceanogr 84:174-184

Gambi C, Lampadariou N, Danovaro R (2010) Latitudinal, longitudinal and bathymetric patterns of abundance, biomass of metazoan meiofauna: importance of the rare taxa and anomalies in the deep Mediterranean Sea. Adv Oceanogr Limnol 1:119-141

Gaston KJ, Spicer JI (2004) Biodiversity: an introduction. Blackwell, Oxford

Giere O (2009) Meiobenthology: the microscopic motile fauna of aquatic sediments. Springer, Berlin

> Gotelli NJ, Colwell RK (2001) Quantifying biodiversity: procedures and pitfalls in the measurement and comparison of species richness. Ecol Lett 4:379-391

$>$ Gray JS (2000) The measurement of marine species diversity, with an application to the benthic fauna of the Norwegian continental shelf. J Exp Mar Biol Ecol 250:23-49

> Gray JS (2002) Species richness of marine soft sediments. Mar Ecol Prog Ser 244:285-297

$>$ Hartzband DJ, Hummon DW (1974) Sub-community structure in subtidal meiobenthic harpacticoida. Oecologia 14:37-51

> Hawkins BA, Giniz-Filho JAF (2004) 'Latitude' and geographic patterns in species richness. Ecography 27: 268-272

> Hillebrand H (2004) Strength, slope and variability of marine latitudinal gradients. Mar Ecol Prog Ser 273:251-267

Hillebrand H, Azovsky AI (2001) Body size determines the strength of the latitudinal diversity gradient. Ecography 24:251-256

> Koleff P, Gaston KJ (2002) The relationships between local and regional species richness and spatial turnover. Glob Ecol Biogeogr 11:363-375

Koleff P, Lennon JJ, Gaston KJ (2003a) Are there latitudinal gradients in species turnover? Glob Ecol Biogeogr 12: 483-498

Koleff P, Gaston KJ, Lennon JJ (2003b) Measuring beta diversity for presence-absence data. J Anim Ecol 72: 367-382 
Lambshead PJD, Boucher G (2003) Marine nematode deepsea biodiversity - hyperdiversity or hype? J Biogeogr 30: 475-485

Lambshead PJD, Tietjen J, Ferrero T, Jensen P (2000) Latitudinal diversity gradients in the deep sea with special reference to North Atlantic nematodes. Mar Ecol Prog Ser 194:159-167

Lambshead PJD, Brown CJ, Ferrero TJ, Mitchell NJ, Smith CR, Hawkins LE, Tietjen J (2002) Latitudinal diversity patterns of deep-sea marine nematodes and organic fluxes: a test from the central equatorial Pacific. Mar Ecol Prog Ser 236:129-136

> Lampadariou N, Tselepides A, Hatziyanni E (2009) Deepsea meiofaunal and foraminiferal communities along a gradient of primary productivity in the eastern Mediterranean Sea. Sci Mar 73:337-345

- Leduc D, Probert PK, Nodder SD (2010) Influence of mesh size and core penetration on estimates of deep-sea nematode abundance, biomass, and diversity. Deep-Sea Res I 57:1354-1362

> Lee MR, Riveros M (2011) Latitudinal trends in the species richness of free-living marine nematode assemblages from exposed sandy beaches along the coast of Chile $\left(18-42^{\circ} \mathrm{S}\right)$. Mar Ecol (in press) doi: 10.1111/j.14390485.2011.00497.x

Levin LA, Etter RJ, Rex MA, Gooday AJ and others (2001) Environmental influences on regional deep-sea species diversity. Annu Rev Ecol Syst 32:51-93

McClain CR, Rex MA, Etter RJ (2009) Patterns in deep-sea macroecology. In: Witman JD, Roy K (eds) Marine macroecology. University of Chicago Press, Chicago, IL, p 65-100

> Melo AS, Rangel TFLVB, Diniz-Filho JAF (2009) Environmental drivers of beta-diversity patterns in New-World birds and mammals. Ecography 32:226-236

Miljutin DM, Gad G, Miljutina MM, Mokievsky VO, Fonseca-Genevois V, Esteves AM (2010) The state of knowledge on deep-sea nematode taxonomy: How many valid species are known down there? Mar Biodivers 40: 143-159

> Mittelbach GG, Steiner CF, Scheiner SM, Gross KL and others (2001) What is the observed relationship between species richness and productivity? Ecology 82: 2381-2396

> Mokievsky VO, Azovsky AI (2002) Re-evaluation of species diversity patterns of free-living marine nematodes. Mar Ecol Prog Ser 238:101-108

Mokievsky VO, Udalov AA, Azovsky AL (2007) Quantitative distribution of meiobenthos in deep-water zones of the World Ocean. Okeanologiya 47:787-813

> Munari C, Mistri M (2008) Biodiversity of soft-sediment benthic communities from Italian transitional waters. J Biogeogr 35:1622-1637

> Muthumbi AW, Vanreusel A, Duineveld G, Soetaert K, Vincx M (2004) Nematode community structure along the continental slope off the Kenyan coast, western Indian Ocean. Int Rev Hydrobiol 89:188-205

Muthumbi AW, Vanreusel A, Vincx M (2011) Taxon-related diversity patterns from the continental shelf to the slope: a case study on nematodes from the Western Indian Ocean. Mar Ecol 32:453-467

Neter J, Kutner MH, Nachtsheim CJ, Wasserman W (1996) Applied linear statistical models, 4th edn. Irwin, Boston, MA
Okuda T, Noda T, Yamamoto T, Ito N, Nakaoka M (2004a) Latitudinal gradient of species diversity: multi-scale variability in rocky intertidal sessile assemblages along the Northwestern Pacific coast. Popul Ecol 46:159-170

Okuda T, Noda T, Yamamoto T, Ito N, Nakaoka M (2004b) Erratum: Latitudinal gradient of species diversity: multiscale variability in rocky intertidal sessile assemblages along the Northwestern Pacific coast. Popul Ecol 46:287

Qian H, Ricklefs RE (2007) A latitudinal gradient in largescale beta diversity for vascular plants in North America. Ecol Lett 10:737-744

Renaud PE, Webb TJ, Bjørgesæter A, Karakassis I and others (2009) Continental-scale patterns in benthic invertebrate diversity: insights from the MacroBen database. Mar Ecol Prog Ser 382:239-252

> Rex MA, Stuart CT, Hessler RR, Allen JA, Sanders HL, Wilson GDF (1993) Global scale latitudinal patterns of species diversity in the deep-sea benthos. Nature 365: 636-639

Rex MA, Stuart CT, Etter RJ (2001) Do deep-sea nematodes show a positive latitudinal gradient of species diversity? The potential role of depth. Mar Ecol Prog Ser 210: 297-298

> Ricotta C, Carranza ML, Avena G (2002) Computing $\beta$-diversity from species-area curves. Basic Appl Ecol 3:15-18

Rodrigues AM, Meireles S, Pereira T, Quintino V (2007) Spatial heterogeneity recognition in estuarine intertidal benthic macrofaunal communities: influence of sieve mesh-size and sampling depth. Hydrobiologia 587:37-50

Rombouts I, Beaugrand G, Iba ez F, Gaspanni S, Chiba S, Legendre L (2009) Global latitudinal variations in marine copepod diversity and environmental factors. Proc Biol Sci 276:3053-3062

> Rose A, Seifried S (2006) Small-scale diversity of Harpacticoida (Crustacea, Copepoda) from an intertidal sandflat in the Jade Bay (German Bight, North Sea). Senckenb Marit 36:109-122

> Rose A, Seifried S, Willen E, George KH and others (2005) A method for comparing within-core alpha diversity values from repeated multicorer samplings, shown for abyssal Harpacticoida (Crustacea: Copepoda) from the Angola Basin. Org Divers Evol 5:3-17

Rosenzweig ML (1995) Species diversity in space and time. Cambridge University Press, Cambridge

Roy K, Jablonski D, Valentine JW, Rosenberg G (1998) Marine latitudinal diversity gradients: tests of causal hypotheses. Proc Natl Acad Sci USA 95:3699-3702

Rybnikov PV, Kondar' DV, Azovsky AI (2003) Properties of the White Sea littoral sediments and their influence on the fauna and distribution of Harpacticoida. Okeanologiya 43:91-102

Seifried S (2004) The importance of a phylogenetic system for the study of deep-sea harpacticoid diversity. Zool Stud 43:435-445

Snelgrove PVR, Austen MC, Boucher G, Heip C and others (2000) Linking biodiversity above and below the marine sediment-water interface. Bioscience 50:1076-1088

Stuart CT, Rex MA, Etter RJ (2003) Large-scale spatial and temporal patterns of deep-sea benthic species diversity. In: Tyler PA (ed) Ecosystems of the deep oceans. Ecosystems of the World, Vol 28. Elsevier, Amsterdam, p 295-311

Thistle D (2001) Harpacticoid copepods are successful in the soft-bottom deep sea. Hydrobiologia 453/454:255-259 
Thrush SF, Hewitt JE, Cummings VJ, Norkko A, Chiantore $M(2010) \beta$-diversity and species accumulation in Antarctic coastal benthos: influence of habitat, distance and productivity on ecological connectivity. PLoS ONE 5:e11899

Tietjen JH (1989) Ecology of deep-sea nematodes from the Puerto Rico Trench area and Hatteras abyssal plain. Deep-Sea Res 36:1579-1594

Udalov AA, Azovsky AI, Mokievsky VO (2005) Depthrelated pattern in nematode size: What does the depth itself really mean? Prog Oceanogr 67:1-23

Vanhove S, Arntz W, Vincx M (1999) Comparative study of the nematode communities on the southeastern Weddell Sea shelf and slope (Antarctica). Mar Ecol Prog Ser 181: 237-256

Editorial responsibility: Hans Heinrich Janssen, Oldendorf/Luhe, Germany
Veech JA, Crist TO (2007) Habitat and climate heterogeneity maintain beta-diversity of birds among landscapes within ecoregions. Glob Ecol Biogeogr 16: 650-656

> Veit-Köhler G, De Troch M, Grego M, Nara Bezerra T and others (2010) Large-scale diversity and biogeography of benthic copepods in European waters. Mar Biol 157: 1819-1835

Whittaker RJ, Willis KJ, Field R (2001) Scale and species richness: towards a general, hierarchical theory of species diversity. J Biogeogr 28:453-470

Willig MR, Kaufman DM, Stevens RD (2003) Latitudinal gradients of biodiversity: pattern, process, scale, and synthesis. Annu Rev Ecol Evol Syst 34:273-309

Submitted: June 30, 2011; Accepted: April 12, 2012

Proofs received from author(s): July 9, 2012 